\title{
Association of behaviour change techniques with effectiveness of dietary interventions among adults of retirement age: a systematic review and meta-analysis of randomised controlled trials
}

Jose Lara ${ }^{1,2^{*}}$, Elizabeth H Evans ${ }^{3}$, Nicola O'Brien ${ }^{3}$, Paula J Moynihan ${ }^{1,3,5}$, Thomas D Meyer ${ }^{4}$, Ashley J Adamson ${ }^{1,3}$, Linda Errington ${ }^{7}$, Falko F Sniehotta ${ }^{3,6}$, Martin White ${ }^{1,3,6}$ and John C Mathers ${ }^{1,2,8}$

\begin{abstract}
Background: There is a need for development of more effective interventions to achieve healthy eating, enhance healthy ageing, and to reduce the risk of age-related diseases. The aim of this study was to identify the behaviour change techniques (BCTs) used in complex dietary behaviour change interventions and to explore the association between BCTs utilised and intervention effectiveness.

Methods: We undertook a secondary analysis of data from a previous systematic review with meta-analysis of the effectiveness of dietary interventions among people of retirement age. BCTs were identified using the reliable CALO-RE taxonomy in studies reporting fruit and vegetable ( $F$ and $V$ ) consumption as outcomes. The mean difference in $\mathrm{F}$ and $\mathrm{V}$ intake between active and control arms was compared between studies in which the BCTs were identified versus those not using the BCTs. Random-effects meta-regression models were used to assess the association of interventions BCTs with $\mathrm{F}$ and $\mathrm{V}$ intakes.

Results: Twenty-eight of the 40 BCTs listed in the CALO-RE taxonomy were identified in the 22 papers reviewed. Studies using the techniques 'barrier identification/problem solving' ( $93 \mathrm{~g}, 95 \%$ confidence interval (Cl) 48 to 137 greater $\mathrm{F}$ and $\mathrm{V}$ intake), 'plan social support/social change' ( $78 \mathrm{~g}, 95 \% \mathrm{Cl} 24$ to 132 greater $\mathrm{F}$ and $\mathrm{V}$ intake), 'goal setting (outcome)' (55 g 95\%Cl 7 to 103 greater F and V intake), 'use of follow-up prompts' (66 g, 95\%Cl 10 to 123 greater $\mathrm{F}$ and $\mathrm{V}$ intake) and 'provide feedback on performance' ( $39 \mathrm{~g}, 95 \% \mathrm{Cl}-2$ to 81 greater $\mathrm{F}$ and $\mathrm{V}$ intake) were associated with greater effects of interventions on $\mathrm{F}$ and $\mathrm{V}$ consumption compared with studies not using these BCTs. The number of BCTs per study ranged from 2 to 16 (median =6). Meta-regression showed that one additional $\mathrm{BCT}$ led to $8.3 \mathrm{~g}(95 \% \mathrm{Cl} 0.006$ to $16.6 \mathrm{~g})$ increase in $\mathrm{F}$ and $\mathrm{V}$ intake.

Conclusions: Overall, this study has identified BCTs associated with effectiveness suggesting that these might be active ingredients of dietary interventions which will be effective in increasing $\mathrm{F}$ and $\mathrm{V}$ intake in older adults. For interventions targeting those in the peri-retirement age group, 'barrier identification/problem solving' and 'plan for social support/social change' may be particularly useful in increasing the effectiveness of dietary interventions.
\end{abstract}

Keywords: Behaviour change techniques, Fruit and vegetables, Retirement, Aging, Randomised controlled trial, Systematic review, Meta-analysis

\footnotetext{
*Correspondence: jose.lara@newcastle.ac.uk

${ }^{1}$ Human Nutrition Research Centre, Newcastle University, Biomedical

Research Building, Campus for Ageing and Vitality, Newcastle upon Tyne NE4 5PL, UK

${ }^{2}$ Institute of Cellular Medicine, Newcastle University, Newcastle, UK

Full list of author information is available at the end of the article
} 


\section{Background}

Adopting healthier dietary patterns is central to the prevention of non-communicable chronic diseases and promotion of healthy ageing [1-3]. The worldwide mortality attributable to low consumption of fruits and vegetables ( $\mathrm{F}$ and $\mathrm{V}$ ) is estimated to be 2.635 million deaths per year and increasing per capita $\mathrm{F}$ and $\mathrm{V}$ consumption to 600 grams per day could reduce the risk of ischaemic heart disease and ischaemic stroke, and of several types of cancer [4] and so reduce total worldwide burden of disease by $1.8 \%$. Thus, the development and implementation of effective dietary interventions have considerable potential to improve health in later life but interventions specifically targeting people of retirement age are lacking. In a recent critical analysis of the evidence on the effectiveness of dietary interventions in those 54- to 70-years old we reported that dietary interventions in this life stage produce increases in $\mathrm{F}$ and $\mathrm{V}$ intake of $88 \mathrm{~g}$ /day which are sustainable in the longer term and likely to be of public health significance [5]. However, there was considerable heterogeneity only partially associated with type of intervention, study design, ethnicity, sex, geographic origin of studies and mode of delivery of interventions. These findings together with previous analysis of interventions delivered in primary care settings [6,7], suggests that there is a need for better understanding of the effective components of such behavioural interventions. Potentially important intervention features include the number of contacts with participants, which are associated with greater, more sustained increases in $\mathrm{F}$ and $\mathrm{V}$ intake and other dietary and lifestyle improvements [5-7]. In addition, the use of particular behaviour change theories and techniques has been previously highlighted as critical aspects of interventions development [8]. Identification of the most effective behaviour change techniques (BCTs) associated with improved outcomes in lifestyle interventions [9] would have considerable utility in informing the development of effective future interventions.

The development of standardised definitions of BCTs, notably the CALO-RE taxonomy, a standardised 40-item taxonomy which can be used to identify BCTs reliably in reports of intervention studies [10], has provided a useful framework for understanding how intervention content is associated with intervention effectiveness. This taxonomy has been applied in recent systematic reviews aiming to identify effective BCTs in increasing physical activity in obese individuals [11] and older subjects [12], limiting gestational weight gain $[13,14]$, promoting weight loss in adults [15] and preventing and managing childhood obesity [16]. However, this approach has not yet been applied in analyses of the effectiveness of dietary interventions. Recently, we systematically reviewed and meta-analysed the evidence on dietary interventions promoting the Mediterranean diet (MD) or any of its components (for example, fruits and vegetables (F and V)), among adults of retirement transition age, with at least three months follow up [5]. Retirement from work is one of the last transitional life events involving important lifestyle changes and may represent a window of opportunity to promote healthier eating patterns in later life. However, the active ingredients associated with greater effectiveness of dietary interventions among this population group remain to be identified. Here, we present a further analysis of those studies in which we aimed to identify the BCTs that are associated with more effective dietary interventions with a particular focus on $\mathrm{F}$ and $\mathrm{V}$ intake. We also evaluated whether behaviour theories were explicitly mentioned in these studies and their association with intervention effectiveness.

\section{Methods}

In a recent systematic review of dietary interventions focusing on the MD or any of its food components and targeting people of retirement age (defined as a study mean or median age between 54 to 70 years), we identified $\mathrm{F}$ and $\mathrm{V}$ intake as the most commonly reported dietary outcome [5]. The protocol for the original systematic review was registered with PROSPERO, the International Prospective Register of Systematic Reviews (Registration number CRD42011001484). Our systematic review is reported according to PRISMA [17] and the detailed methodology together with the PRISMA flow chart and checklist of the original review have been described elsewhere [5], so only pertinent details are reported here.

In March 2013, 12 electronic databases, namely Medline, Embase, PsycInfo, Scopus, Web of Science, CINAHL, ASSIA, Cochrane Database of Systematic Reviews, CAB Abstracts, Conference Papers Index, WorldCat Dissertations database and Index to Theses, were searched for randomised controlled trials (RCTs) of interventions promoting healthy dietary patterns, such as the MD or any of its component food groups (for example, F and V; legumes or pulses; nuts and seeds; unrefined cereals; olive oil; fish; moderate consumption of wine; low consumption of meat and meat products). To measure sustained behaviour change, only intervention studies with a follow-up of $\geq 3$ months were included. The primary outcome was dietary change and this analysis focuses on the fruit and/or vegetable intake (in grams per day) since this was the outcome common to all studies reviewed. The literature searches yielded 22 studies which provided data for meta-analysis and for evaluating behaviour change features of these interventions [18-39].

\section{Behaviour change techniques}

We used the CALO-RE taxonomy [10], a reliable 40-item taxonomy of standardised BCT definitions used in physical activity and healthy eating interventions, which has been 
used recently to evaluate potentially active ingredients in complex behaviour change of interventions $[11,13,14,16]$. Intervention content from each of the 22 articles was reviewed and coded for the presence (or absence) of each of the 40 BCTs in the CALO-RE taxonomy. When a protocol of the study was published, this was also evaluated. Two reviewers (JL and EE) were trained by an experienced health psychologist $(\mathrm{NH})$ in the use of the BCT-taxonomy. The two reviewers (JL and EE) coded the intervention content independently and discrepancies between them were resolved through discussion with a third reviewer $(\mathrm{NH})$ at each stage of the review process and a consensus approach used. Behaviour change theories used in these studies, if explicitly declared, were also recorded.

\section{Statistical analysis}

Review Manager (RevMan Version 5.1 for Windows Copenhagen: The Nordic Cochrane Centre, The Cochrane Collaboration, 2011) and Stata (Stata/SE 11.2 for Windows; StataCorp LP, College Station, TX, USA) were used to pool and analyse results from the individual studies.

Pooled results are reported as mean differences with 95\% confidence intervals (Cis) and with two-tailed $P$-values. A random effects model accounting for inter-study variation was used, thereby minimising potential bias due to methodological differences between studies. Multiple dietary intervention arms from three studies were included in the meta-analysis. As suggested by Higgins et al. [40] excessive weightings from 'double counts' originating from the 'shared' group (that is, control group), were controlled by splitting the sample size of the shared group into approximately equal smaller groups for the comparisons; the means and standard deviations were left unchanged. When available, we used results from multivariate models with the most complete adjustment for potential confounders reported in original studies. Analysis was performed to investigate associations between BCTs identified in complex interventions and in the effectiveness of the interventions in increasing $\mathrm{F}$ and $\mathrm{V}$ intake by comparing effectiveness of those studies which did, and those which did not, employ the specified BCT. To increase statistical power and reduce the likelihood of type-1 error associated with multiple comparisons we limited this analysis to the most frequently reported BCTs (that is, those BCTs which were reported in at least five studies).

Statistical heterogeneity was evaluated by using the $I^{2}$ statistic [40,41]; as proposed by Ioannidis et al. [42] the 95\% CIs for $I^{2}$ were calculated using the Higgins et al. method [43]. Where $I^{2}$ was $>50 \%$, the degree of heterogeneity was considered high.

Publication bias was appraised by visual inspection of a funnel plot of effect size against the standard error (SE) for each study, with asymmetry assessed formally with Egger's regression test [44].
We performed meta-regression analysis with restricted maximum likelihood estimation to assess the relationship of the number of behaviour techniques extracted from each study with changes in $\mathrm{F}$ and $\mathrm{V}$ consumption.

\section{Results}

Twenty-two studies provided data for meta-analysis and coding of BCTs [18-39]. The pooled study populations included 63,189 participants who were followed-up for 19 months on average (range 4 to 58 months). The mean ages of participants in these studies ranged from 54 to 67 years. Four studies recruited women only and two men only (see Additional file 1). A funnel plot of the mean differences against SEs of all studies did not indicate important asymmetry, which was confirmed by the Egger's regression test $(P=0.394)$.

\section{Behaviour change techniques meta-analysis}

Twenty-eight out of $40 \mathrm{BCTs}$ in the CALO-RE taxonomy were identified in the studies reviewed. The five most commonly reported BCTs were 'goal setting (behaviour)', 'provide information on consequences of behaviour in general', 'provide instruction on how to perform the behaviour', 'provide feedback on performance' and 'goal setting (outcome)' (Table 1). The 12 BCTs from the CALO-RE taxonomy which were not identified in the reviewed studies were 'provide information about others' approval', 'prompt review of outcome goals', 'prompt rewards contingent on effort or progress towards behaviour', 'shaping', 'prompting generalisation of a target behaviour', 'prompting focus on past success', 'prompt identification as role model/position advocate', 'prompt anticipated regret', 'fear arousal', 'prompt use of imagery', 'general communication skills training' and 'stimulate anticipation of future rewards'. The number of incorporated BCTs per study ranged from 2 to 16, with a median of 6 BCTs per study.

Meta-analysis of change in intake of $\mathrm{F}$ and $\mathrm{V}$ in response to intervention was carried out based on the presence or absence of specific BCTs which were reported in at least five RCTs. Results showed that studies incorporating the BCTs 'barrier identification/problem solving' (93 g, 95\%CI 48 to 137 greater $\mathrm{F}$ and $\mathrm{V}$ intake) (Figure 1), 'plan social support/social change' (78 g, 95\% CI 24 to 132 greater $\mathrm{F}$ and V intake) (Figure 2), 'use of follow-up prompts' (66 g, 95\% CI 10 to 123 greater $\mathrm{F}$ and $\mathrm{V}$ intake) and 'goal setting (outcome)' (55 g 95\% CI 7 to 103 greater F and V intake) (Table 2) were associated with conclusive and clinically important improvements in $\mathrm{F}$ and $\mathrm{V}$ intakes. In addition, there was weaker evidence that studies employing the BCT 'provide feedback on performance' were associated with greater $\mathrm{F}$ and $\mathrm{V}$ intake than studies not incorporating this BCT in their interventions (between groups difference 39 g 95\%CI -2 to 81 ) (Table 2). Conversely, studies reporting use of the BCTs 'motivational interviewing' and 'provide 
Table 1 Frequency of use of the behaviour change techniques in the 22 studies reviewed (CALO-RE taxonomy item) Behaviour change techniques identified

(5) Goal setting behaviour 23

(1) Provide information on consequences of behaviour in general

(21) Provide instruction on how to perform the behaviour

(19) Provide feedback on performance

(6) Goal setting outcome

(2) Provide information on consequences of behaviour to the individual

(27) Use of follow-up prompts

(8) Barrier identification/problem solving

(37) Motivational interviewing

(22) Model/Demonstrate the behaviour

(29) Plan social support/social change

(10) Prompt review of behavioural goals

(24) Environmental restructuring

(7) Action planning

(28) Facilitate social comparison

(16) Prompt self-monitoring of behaviour

(23) Teach to use prompts/cues

(26) Prompt practice

(4) Provide normative information about others' behaviour

(13) Provide rewards contingent on successful behaviour

(25) Agree behavioural contract

(17) Prompt self-monitoring of behavioural outcome

(20) Provide information on where and when to perform the behaviour

(35) Relapse prevention/coping planning

(33) Prompt self talk

(9) Set graded tasks

(36) Stress management/emotional control training

(38) Time management

information on consequences of behaviour to the individual' were associated with significantly smaller improvements in $\mathrm{F}$ and $\mathrm{V}$ intakes in comparison with studies not using these BCTs (Table 2). Forest plots for each of the BCTs investigated in Table 2 are provided as supplementary material [see Additional file 1].

Meta-regression showed that one additional BCT led to $8.3 \mathrm{~g}$ (95\% CI 0.006 to $16.6 \mathrm{~g}$ ) increase in $\mathrm{F}$ and $\mathrm{V}$ intake (Figure 3).

\section{Theoretical basis of interventions}

Fourteen studies reported the use of behaviour change theories in the development of their intervention and eight studies did not report use of any theory. Eight of the 14 studies reported use of a combination of two or more behaviour change theories while the other six studies reported using a single theory. The behaviour change theories declared in the reviewed studies included social cognitive theory $(n=5)$, social learning theory $(n=4)$, the transtheoretical model $(\mathrm{n}=4)$, theory of planned behaviour $(\mathrm{n}=2)$, social support $(\mathrm{n}=2)$, and health behaviour model $(n=2)$, self-management $(n=1)$. Subgroup analysis showed that studies $(n=14)$ reporting the use of behaviour change theories reported changes in $\mathrm{F}$ and $\mathrm{V}$ intake which were nearly $50 \%$ greater ( $94.7 \mathrm{~g} /$ day $95 \% \mathrm{CI} 49.1$ to $140.3 \mathrm{~g}$ ) than in those studies not reporting use of a behaviour change theory $(66.5 \mathrm{~g} /$ day $95 \% \mathrm{CI}-7.7$ to $140.7 \mathrm{~g})$ but the difference between these groups $(28.2 \mathrm{~g} 95 \% \mathrm{CI}-58.9$ to 115.3) was not statistically significant. Studies reporting the use of a single behaviour change theory achieved $67 \%$ greater increase mean $\mathrm{F}$ and $\mathrm{V}$ intakes $(\mathrm{n}=6)(121.6 \mathrm{~g} /$ day $95 \%$ CI 56.8 to $186.5 \mathrm{~g}$ ) than those studies reporting use of a combination of behaviour change theories $(n=8)$ (72.8 g/day 95\%CI 11.9 to 133.7 ) but the difference between these groups $(48.8 \mathrm{~g} 95 \% \mathrm{CI}-40.1$ to 137.7$)$ was not statistically significant. 


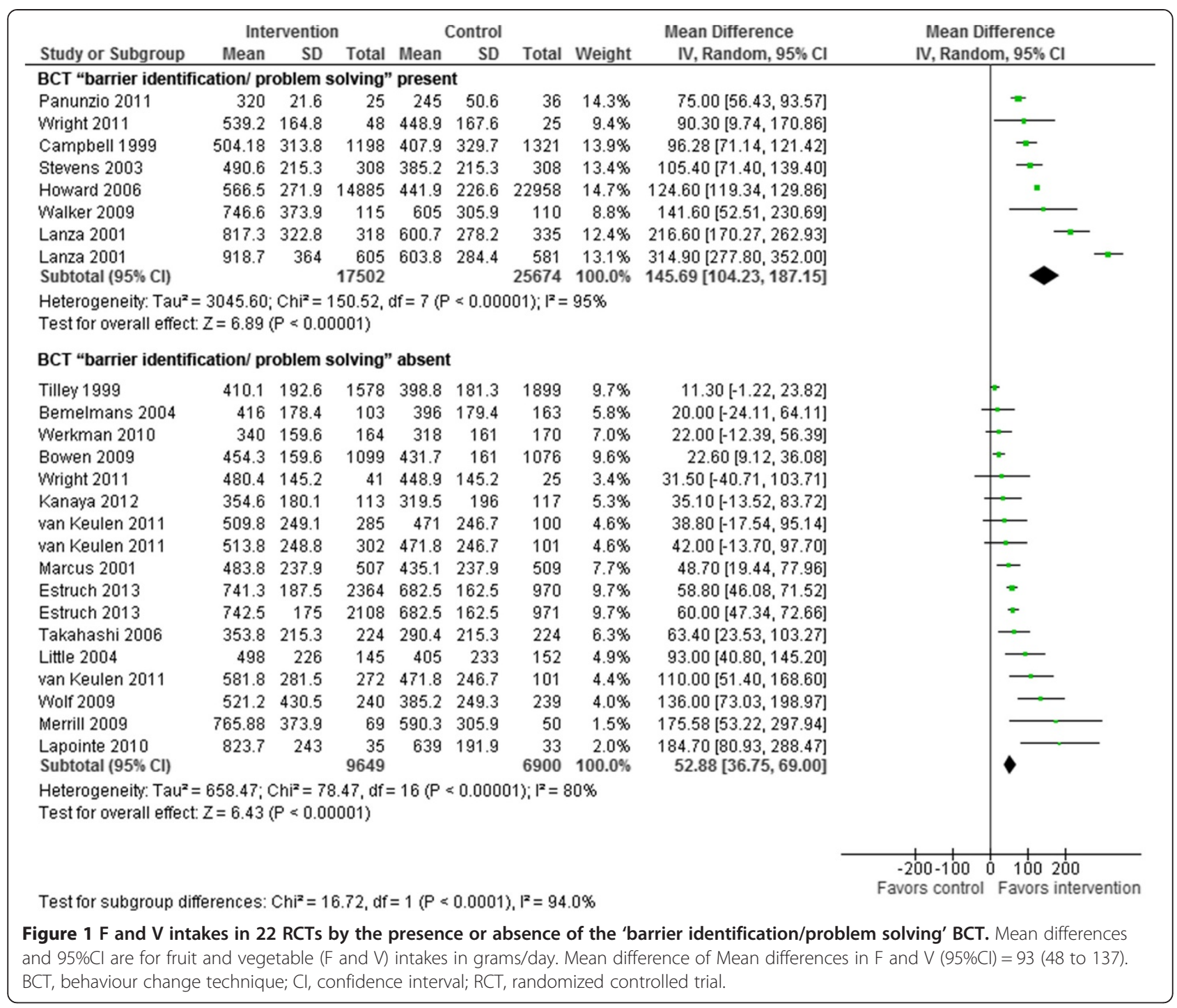

\section{Discussion}

\section{Statement of principal findings}

This analysis suggests that use of BCTs, including barrier identification/problem solving, plan social support/social change, use of follow-up prompts and goal setting (outcome), is associated with enhanced effectiveness of dietary interventions. Using these BCTs in the intervention design resulted in increases in $\mathrm{F}$ and $\mathrm{V}$ intakes which were 60 to $90 \mathrm{~g} /$ day greater than when these BCTs were not utilised in the intervention.

\section{Strengths and weaknesses of the study}

To our knowledge, this is the first study evaluating the association of BCTs use in dietary interventions in promoting sustained increases in $\mathrm{F}$ and $\mathrm{V}$ intake among individuals of retirement transition age. The strengths of this study include a rigorous methodology in the systematic review of the literature and the application of a well-established BCT taxonomy to identify BCT use. Although it is possible that the findings of this study might be confounded by unexplored covariates, previous analysis published elsewhere [5] showed that other aspects of the populations or interventions reviewed, such as mode of delivery of the intervention, health status of participants, follow-up time or ethnicity, were not related to $\mathrm{F}$ and $\mathrm{V}$ intakes and, therefore, are unlikely to confound the present findings. In addition, we limited the effect of multiple comparisons by restricting the comparisons to only those BCTs observed in five or more studies. Among the limitations are the small number of studies $(n=22)$ available and the high level of unexplained heterogeneity in this meta-analysis. In addition, from the studies reviewed we cannot confirm that the BCTs identified in these interventions were delivered as intended. The subgroup analyses are exploratory and the results obtained should be interpreted with caution because of the small numbers of 


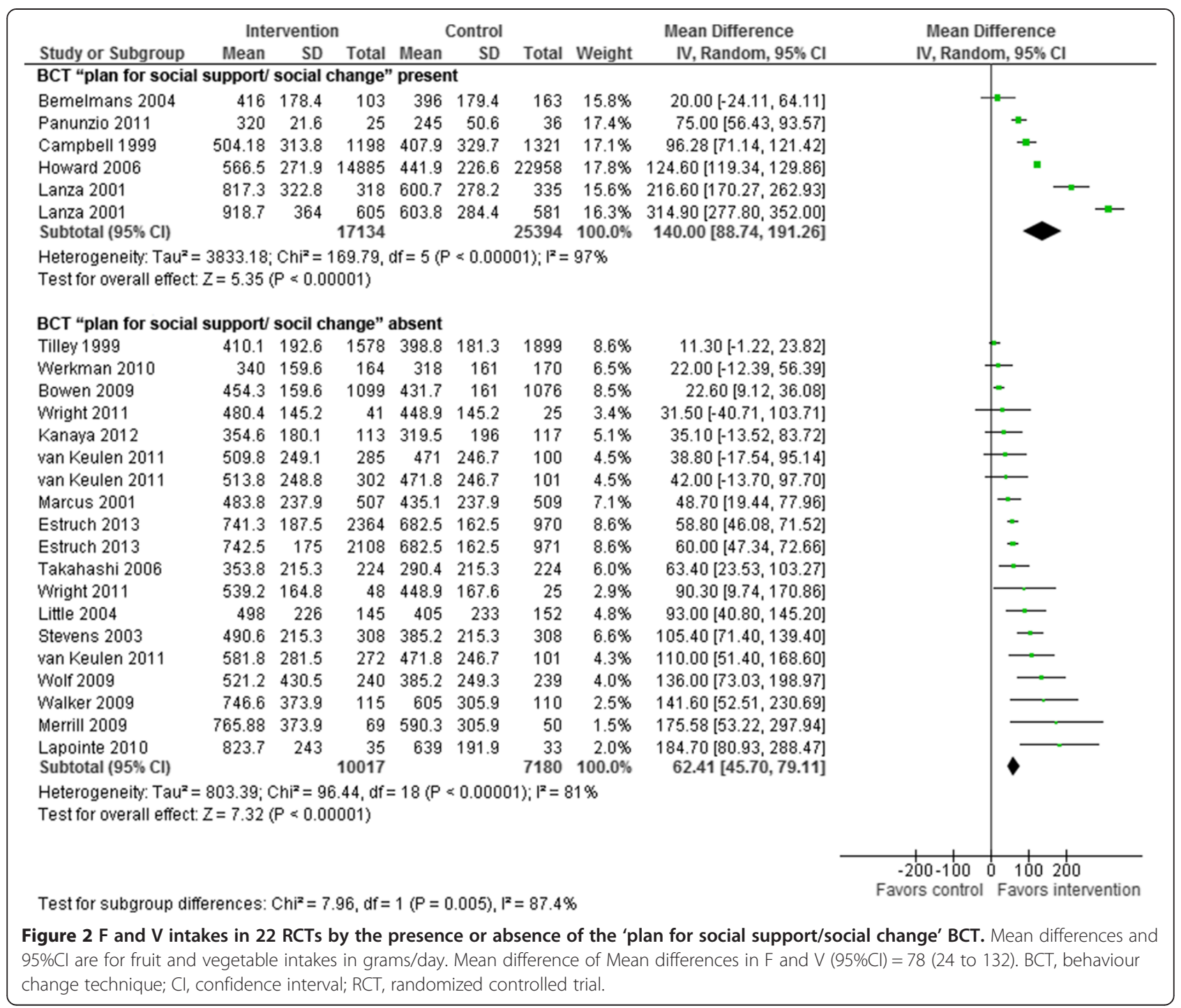

studies in each sub-group and the post hoc nature of the analysis. The limited number of studies available determined that our analysis focused on examining the associations between $\mathrm{F}$ and $\mathrm{V}$ intake in studies with the presence or absence of specific BCTs and associations of combinations of $\mathrm{BCTs}$ with intervention effects on $\mathrm{F}$ and $\mathrm{V}$ intake could not be evaluated.

\section{Scientific analysis of findings}

Research into the effectiveness of including specific $\mathrm{BCT}$ s in dietary interventions is still limited. Using an earlier version of the BCT taxonomy comprising 26 BCTs, Michie et al. [9], reported that the inclusion of techniques derived from Control Theory ('prompt intention formation', 'prompt specific goal setting', 'prompt review of behavioural goals', 'prompt self-monitoring of behaviour', 'provide feedback on performance') was associated with increased effectiveness of interventions of healthy eating and physical activity compared with those which did not include such techniques.

To our knowledge, no other systematic review has evaluated the use of the CALO-RE taxonomy on the effectiveness of dietary interventions. However, four published systematic reviews, focusing on physical activity $[11,12]$, gestational weight gain $[13,14]$, prevention and management of childhood obesity [16] and weight management [15] have used the CALO-RE taxonomy. Gardner et al. [13] found no obvious differences in the BCTs employed between effective and ineffective interventions, while French et al. [12] reported that self-regulatory techniques were associated with lower levels of both self-efficacy and physical activity. The remaining reviews have identified a range of BCTs but only 'prompt practice' $[11,16]$ and 'provision of information on the consequences of behaviour to the individual' $[14,16]$ have been identified repeatedly in two systematic reviews. In addition, only 
Table 2 Association of behaviour change techniques (BCTs) with fruit and vegetable intakes in 22 intervention studies

\begin{tabular}{|c|c|c|c|c|c|c|c|}
\hline BCT & $\begin{array}{l}\text { Number of studies } \\
\text { or subgroups BCT } \\
\text { present Yes (No) }\end{array}$ & $\begin{array}{l}\text { Sample size BCT } \\
\text { present Yes (No) }\end{array}$ & $\begin{array}{l}\text { BCT present Mean } \\
\text { difference }(95 \% \mathrm{Cl})\end{array}$ & $\mathrm{I}^{2}(95 \% \mathrm{Cl})$ & $\begin{array}{l}\text { BCT absent Mean } \\
\text { difference }(95 \% \mathrm{Cl})\end{array}$ & $\mathrm{I}^{2}(95 \% \mathrm{Cl})$ & $\begin{array}{l}\text { (Mean difference of Mean } \\
\text { differences }(95 \% \mathrm{Cl})) P\end{array}$ \\
\hline Motivational interviewing & $7(18)$ & $10,183(49503)$ & 52.8 (33.1 to 72.8$)$ & $81(61$ to 90$)$ & 105.1 (71.4 to 138.7) & 97 (95 to 97) & $(-52(-91$ to -13$)) 0.009$ \\
\hline $\begin{array}{l}\text { Provide information on consequences } \\
\text { of behaviour to the individual }\end{array}$ & $11(14)$ & 12,488 (9394) & 60.1 (45.0 to 75.3 ) & $62(27$ to 80$)$ & 109.6 (64.6 to 154.9$)$ & 96 (95 to 97 ) & $(-49(-97$ to -2$)) 0.040$ \\
\hline Prompt review of behavioural goals & $5(20)$ & $7,163(52562)$ & 69.1 (55.8 to 82.3) & 53 (0 to 83) & $92.9(59.7$ to 126.1$)$ & 97 (96 to 98$)$ & $(-24(-60$ to 12$)) 0.190$ \\
\hline Goal setting (behaviour) & $23(2)$ & $59,323(402)$ & 89.0 (63.6 to 114.5$)$ & 97 (96 to 98 ) & $95.7(-63.1$ to 254.4$)$ & $88(N / A)$ & $(-7(-166$ to 153$)) 0.940$ \\
\hline Model/Demonstrate the behaviour & $6(19)$ & $3,258(56467)$ & $91.3(56.9$ to 125.7$)$ & $71(32$ to 87$)$ & 85.0 (55.9 to 114.2 ) & 95 (97 to 98 ) & $(6(-39$ to 51$)) 0.790$ \\
\hline $\begin{array}{l}\text { Provide instruction on how to } \\
\text { perform the behaviour }\end{array}$ & $15(10)$ & $53,717(6008)$ & 99.5 (69.6 to 129.5$)$ & 97 (96 to 98) & 67.8 (34.5 to 101.2$)$ & 78 (59 to 88 ) & $(32$ (-13 to 77$)) 0.170$ \\
\hline $\begin{array}{l}\text { Provide information on consequences } \\
\text { of behaviour in general }\end{array}$ & $18(7)$ & $53,298(6427)$ & $97.8(67.6$ to 127.9$)$ & 97 (96 to 98$)$ & 66.7 (32.3 to 101.1) & 86 (74 to 93$)$ & (31 (-15 to 77)) 0.180 \\
\hline Provide feedback on performance & $14(11)$ & $54,563(5162)$ & 102.5 (68.9 to 136.0$)$ & 98 (97 to 98 ) & 63 (37.9 to 88.0) & $78(60$ to 87$)$ & (39 (-2 to 81)) 0.060 \\
\hline Goal setting (outcome) & $11(14)$ & $43,702(16023)$ & 118.1 (74.3 to 161.9) & 97 (96 to 98 ) & 62.8 (43.5 to 82.2) & 83 (73 to 90$)$ & $(55$ (7 to 103)) 0.020 \\
\hline Use of follow-up prompts & $9(16)$ & 41,627 (18098) & 127.4 (74.1 to $180 . .7)$ & 95 (92 to 97$)$ & 60.9 (43.4 to 78.4$)$ & 86 (78 to 91$)$ & $(66$ (10 to 123$)) 0.020$ \\
\hline
\end{tabular}

Mean differences and $95 \% \mathrm{Cl}$ are for fruit and vegetable ( $\mathrm{F}$ and $\mathrm{V}$ ) intakes in grams/day. $P$-values correspond to $\mathrm{Chi}$ square test for difference between groups (that is, $\mathrm{BCT}$ present versus $\mathrm{BCT}$ absent). $\mathrm{Cl}$, confidence interval. 


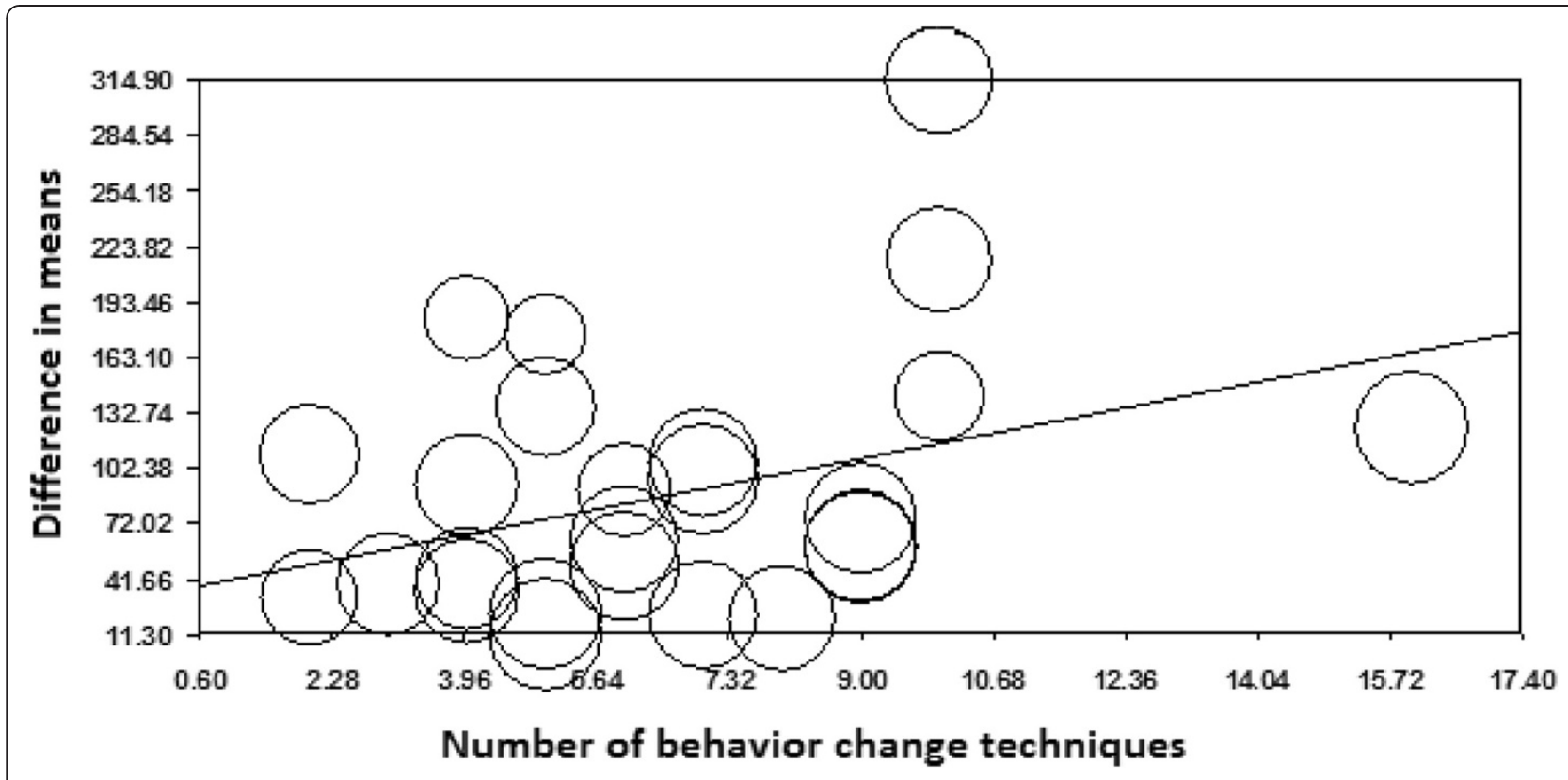

Figure 3 Meta-regression of number of BCTs on overall fruit and vegetable intake. Number of $B C T s$. Slope $=8.28, Q=3.84, d . f .=1$, $P=0.049$. The circle size reflects the weight that a study obtained in the meta-regression.

Hartmann-Boyce et al. [15], reported BCTs associated with lower effectiveness of interventions; these were 'prompting focus on past success' and 'prompt self-talk' (Table 3).

None of these systematic reviews, including ours, replicated the findings of a clear clustering of BCTs associated with the Control Theory as the key BCTs associated with better dietary outcomes reported by Michie et al. [9]. Of the five BCTs identified in the present study, only 'plan social support/social change' was also identified by Olander et al. [11] as associated with positive changes in physical activity self-efficacy among obese individuals. The median number of BCTs, as well as the most frequently reported BCTs, identified in the present study are similar to the BCTs identified in these studies $[11,13,14,16]$. Differences in the effective BCTs identified in different reports might result from differences in the population groups studied; therefore, specific BCTs useful in a particular population group might not be equally useful in a different population group.

BCTs congruent with the Control Theory were associated with greater effectiveness of lifestyle interventions in the report by Michie et al. [9] but the present study revealed four BCTs which were effective in increasing $\mathrm{F}$ and $\mathrm{V}$ and which may also be part of several behaviour change theories. The two BCTs which were more strongly associated with improved $\mathrm{F}$ and $\mathrm{V}$ intakes in our systematic review, 'barrier identification/problem solving' and 'social support' are congruent with the Social Cognitive Theory [45]. In addition, significant, but more moderate, effects on intervention effectiveness were observed for BCTs congruent with the Operant Learning Theory [46]. However, it is important to note that individual BCTs are not exclusive to specific behaviour change theory.

Analysis of current evidence on the impact of the extent and type of theory on diet and physical activity interventions suggests that theory is not often used or reported and that its relationship with intervention effectiveness is weak [47]. Hill et al. [14] found that studies based on theory were as effective as non-theory-based studies at limiting gestational weight gain. These findings are supported by our observation of no significant differences in effectiveness of theory-based versus non theory-based interventions.

Our results showed a significant trend towards greater improvements in $\mathrm{F}$ and $\mathrm{V}$ intake with employment of more BCTs per study. This finding, however, contradicts previous evidence suggesting that it might be more important to focus on a few effective BCTs, rather than a greater number of BCTs, when designing dietary interventions $[9,13,14]$.

Twelve BCTs from the CALO-RE taxonomy were not identified in any of the dietary interventions reviewed here, while 16 BCTs were reported by fewer than 5 studies and, therefore, were not considered in this analysis. More research on the potential usefulness of this sub-set of less frequently used BCTs in improving the effectiveness of dietary interventions is required.

Previously, we reported a significant positive association between number of contacts within the intervention and greater increases in $\mathrm{F}$ and $\mathrm{V}$ intakes, suggesting the importance of features of interventions on their effectiveness [5]. These results are supported by a recent report from the U. S. Preventive Services Task Force (USPSTF) on behavioural counselling to promote a healthful diet and physical activity 
Table 3 Published systematic reviews applying the CALO-RE taxonomy of behaviour change techniques

\begin{tabular}{|c|c|c|c|}
\hline Outcome reviewed & Reference & $\begin{array}{l}\text { BCTs identified as with greater effectiveness } \\
\text { of interventions }\end{array}$ & $\begin{array}{l}\text { BCTs identified as with lower } \\
\text { effectiveness of interventions }\end{array}$ \\
\hline \multirow{8}{*}{$\begin{array}{l}\text { Increasing physical activity } \\
\text { in obese individuals }\end{array}$} & \multirow[t]{3}{*}{ Olander (2013) [11] } & - 'teach to use prompts/cues' & \\
\hline & & - 'prompt practice' & \\
\hline & & $\begin{array}{l}\text { - 'prompt rewards contingent on effort or progress } \\
\text { towards behaviour' }\end{array}$ & \\
\hline & \multirow[t]{5}{*}{ French (2014) [12] } & \multirow[t]{5}{*}{ - None } & • 'setting behavioural goals' \\
\hline & & & • 'prompting self-monitoring of behaviour' \\
\hline & & & • 'planning for relapses' \\
\hline & & & • 'providing normative information' \\
\hline & & & • 'providing feedback on performance' \\
\hline \multirow[t]{5}{*}{$\begin{array}{l}\text { Limiting gestational } \\
\text { weight gain }\end{array}$} & Gardner (2011) [13] & $\begin{array}{l}\text { - No obvious differences in the behaviour change } \\
\text { techniques employed between effective and } \\
\text { ineffective interventions }\end{array}$ & \\
\hline & \multirow[t]{4}{*}{ Hill (2013) [14] } & $\begin{array}{l}\text { - 'provision of information on the consequences } \\
\text { of behaviour to the individual' }\end{array}$ & \\
\hline & & • 'motivational interviewing' & \\
\hline & & • 'behavioural self-monitoring' & \\
\hline & & - 'providing rewards contingent on successful behaviour' & \\
\hline \multirow{4}{*}{$\begin{array}{l}\text { Promoting weight loss } \\
\text { in adults }\end{array}$} & \multirow{4}{*}{$\begin{array}{l}\text { Hatmann-Boyce } \\
\text { (2014) [15] }\end{array}$} & - 'provide information about others' approval' & - 'prompting focus on past success' \\
\hline & & - 'provide normative information about others behaviour' & · 'prompt self-talk' \\
\hline & & - 'model/demonstrate the behaviour' & \\
\hline & & • 'facilitate social comparison' & \\
\hline \multirow[t]{6}{*}{$\begin{array}{l}\text { Preventing and managing } \\
\text { childhood obesity }\end{array}$} & \multirow[t]{6}{*}{ Martin (2013) [16] } & $\begin{array}{l}\text { - 'provide information on the consequences of } \\
\text { behaviour to the individual' }\end{array}$ & \\
\hline & & • 'environmental restructuring' & \\
\hline & & - 'prompt practice' & \\
\hline & & - 'prompt identification as role model/position advocate' & \\
\hline & & • 'stress management/emotional control training' & \\
\hline & & •'general communication skills training' & \\
\hline
\end{tabular}

in adults without pre-existing cardiovascular disease (CVD) or its risk factors suggesting that interventions of moderate to high-intensity, but not low-intensity, were associated with better results $[6,7]$.

\section{Implications for health and policymaking}

Worldwide increases in life expectancy are increasing the proportion of older adults in most populations with consequent increases in the proportion of retirees [48]. Retirement has been associated with increases in body weight and waist circumference, well known risk factors for CVD [49], and health promotion at retirement is of considerable importance to retirees and policy makers [50]. The findings of this study will contribute to the development of effective dietary interventions incorporating BCTs that have proven useful among adults of retirement age. Interventions which incorporated 'barrier identification/ problem solving' and 'plan social support/social change' $\mathrm{BC}$ Ts resulted in approximately 93 and $78 \mathrm{~g}$ /day extra F and $\mathrm{V}$, respectively, (equivalent to about a portion of $\mathrm{F}$ and $\mathrm{V}$ according to UK standards [51]) compared with those not using these BCTs. Based on average population intakes of $\mathrm{F}$ and $\mathrm{V}$ in the UK (4.2 portions or $336 \mathrm{~g} /$ day, in adults 19 to 64 years; 4.4 portions or $352 \mathrm{~g} /$ day in older adults 65-years old and older), interventions incorporating more effective BCTs could make a significant difference in achieving the WHO recommendation of at least $400 \mathrm{~g} \mathrm{~F}$ and \&V/day [52].

Several systematic reviews and meta-analyses of cohort studies indicate that small differences in $\mathrm{F}$ and $\mathrm{V}$ intake, such as the ones observed in the present study, are associated with reductions in the risk for cardiovascular events with significant potential for population impact. Increasing $\mathrm{F}$ and $\mathrm{V}$ consumption by around 100 to $150 \mathrm{~g} /$ day decreases the risk of stroke by $11 \%$ [53,54], coronary heart disease by $4 \%$ to $7 \%[54,55]$ and diabetes by $10 \%$ to $14 \%[56,57]$. Future research should test the effect of tailored interventions using the BCTs identified 
in this systematic review. Our study focussed on those 54- to 70-years old, and whether the BCTs identified in this study are applicable to other age groups remains to be tested. The CALO-RE taxonomy of BCTs [10] is a useful tool and its adoption should enhance the description of dietary and other lifestyle interventions, thus allowing more objective comparisons between studies.

\section{Conclusions}

In conclusion, this systematic review showed that RCTs of dietary interventions targeting people of retirement age used a range of BCTs, some of which were associated with greater intervention effectiveness. Dietary interventions in the retirement transition are likely to yield long-term health benefits and certain features of interventions, such as a greater number of contacts and inclusion of specific BCTs, notably 'barrier identification/problem solving', 'plan social support/social change', 'goal setting (outcome)' and 'use of follow-up prompts', appear to enhance the effectiveness of such interventions. These findings may help in developing more effective dietary interventions among individuals of retirement age.

\section{Additional file}

Additional file 1: Table S1. Characteristics of RCTs and features of dietary interventions among adults of retirement age. Figure S1. Number of Behaviour change techniques used in the reviewed studies. Figure S2. F\&V intakes in RCTs by the presence or absence of the "use of follow-up prompts" BCT. Figure S3. F\&V intakes in RCTs by the presence or absence of the "goal setting (outcome)" BCT. Figure S4. F\&V intakes in RCTs by the presence or absence of the "provide feedback on performance" $\mathrm{BCT}$. Figure S5. F\&V intakes in RCTs by the presence or absence of the "provide information on consequences of behaviour in general" BCT. Figure S6. F\&V intakes in RCTs by the presence or absence of the "provide instruction on how to perform the behaviour" BCT. Figure S7. F\&V intakes in RCTs by the presence or absence of the "model/demonstrate the behaviour" BCT. Figure S8. F\&V intakes in RCTs by the presence or absence of the "goal setting (behaviour)" BCT. Figure S9. F\&V intakes in RCTs by the presence or absence of the "Prompt review of behavioural goals" BCT. Figure S10. F\&V intakes in RCTs by the presence or absence of the "Provide information on consequences of behaviour to the individual" $\mathrm{BC}$.

Figure S11. F\&V intakes in RCTs by the presence or absence of the "motivational interviewing" BCT.

\section{Competing interests}

The authors declare that they have no competing interests.

\begin{abstract}
Authors' contributions
JCM, MW, PJM and FFS conceived the study. JL, NH, PJM, TDM, AA, LE, FFS, MW and JCM designed the study, while PJM, TDM, AA, FFS, MW and JCM oversaw its implementation. LE performed database searches. JL and EE coordinated and performed study selection, data extraction and quality assessment. JL, MW and JCM planned the analysis and interpreted the results, and $J L$ conducted the meta-analyses and meta-regression. JL and JCM wrote the first draft. All authors reviewed the study findings, and read and approved the final manuscript.
\end{abstract}

\section{Acknowledgements}

We thank the following colleagues at Newcastle University who helped with literature searching and/or data extraction: Dr Ben Heaven, Dr Laura Brown,
Dr Satomi Miwa, Dr C. Alexandra Munro, Yi (Frances) Wong, Evelyn Barron and Caroline Shaw.

This paper was produced by the LiveWell Programme which is funded by the Lifelong Health and Wellbeing (LLHW) Cross-Council Programme initiative in partnership with the UK Health Departments. JCM's research through the Centre for Brain Ageing and Vitality is also funded by the LLHW initiative. The LLHW Funding Partners are: Biotechnology and Biological Sciences Research Council, Engineering and Physical Sciences Research Council, Economic and Social Research Council, Medical Research Council, Chief Scientist Office of the Scottish Government Health Directorates, National Institute for Health Research/ The Department of Health, The Health and Social Care Research \& Development of the Public Health Agency (Northern Ireland), and Wales Office of Research and Development for Health and Social Care, Welsh Assembly Government. During this study, MW and AA were partly funded and FFS was fully funded as members of Fuse, the Centre for Translational Research in Public Health, a UK Clinical Research Collaboration (UKCRC) Public Health Research Centre of Excellence. Funding for Fuse from the British Heart Foundation, Cancer Research UK, Economic and Social Research Council, Medical Research Council, and the National Institute for Health Research, under the auspices of the UKCRC, is gratefully acknowledged. LR is supported by the National Institute for Health Research (NIHR) Newcastle Biomedical Research Centre and Unit based at Newcastle upon Tyne Hospitals NHS Foundation Trust and Newcastle University.

AA is supported by a NIHR Research Professorship.

The views expressed in this paper are those of the authors and do not necessarily represent those of the funders listed above.

\section{Author details}

${ }^{1}$ Human Nutrition Research Centre, Newcastle University, Biomedical Research Building, Campus for Ageing and Vitality, Newcastle upon Tyne NE4 5PL, UK. ${ }^{2}$ Institute of Cellular Medicine, Newcastle University, Newcastle, UK. ${ }^{3}$ Institute of Health and Society, Newcastle University, Newcastle, UK. ${ }^{4}$ Department of Psychiatry \& Behavioral Sciences, University of Texas Health Science Center, Houston, TX, USA. ${ }^{5}$ Centre for Oral Health Research, Newcastle University, Newcastle, UK. ${ }^{6}$ Fuse, UKCRC Centre for Translational Research in Public Health, Newcastle, UK. 7Walton Library, Newcastle University, Newcastle, UK. ${ }^{8}$ Centre for Brain Ageing and Vitality, Newcastle University, Newcastle, UK.

Received: 22 July 2014 Accepted: 9 September 2014

Published online: 07 October 2014

\section{References}

1. Sofi F, Cesari F, Abbate R, Gensini GF, Casini A: Adherence to Mediterranean diet and health status: meta-analysis. BMJ 2008, 337:a1344.

2. Sofi F, Abbate R, Gensini GF, Casini A: Accruing evidence on benefits of adherence to the Mediterranean diet on health: an updated systematic review and meta-analysis. Am J Clin Nutr 2010, 92:1189-1196.

3. Murray CJ, Richards MA, Newton JN, Fenton KA, Anderson HR, Atkinson C, Bennett D, Bernabé E, Blencowe H, Bourne R, Braithwaite T, Brayne C, Bruce NG, Brugha TS, Burney P, Dherani M, Dolk H, Edmond K, Ezzati M, Flaxman AD, Fleming TD, Freedman G, Gunnell D, Hay RJ, Hutchings SJ, Ohno SL, Lozano R, Lyons RA, Marcenes W, Naghavi M, et al: UK health performance: findings of the Global Burden of Disease Study 2010. Lancet 2013, 381:997-1020

4. Lock K, Pomerleau J, Causer L, Altmann DR, McKee M: The global burden of disease attributable to low consumption of fruit and vegetables: implications for the global strategy on diet. Bull World Health Organ 2005, 83:100-108.

5. Lara J, Hobbs N, Moynihan P, Meyer T, Adamson A, Errington L, Rochester L, Sniehotta F, White M, Mathers J: Effectiveness of dietary interventions among adults of retirement age: a systematic review and meta-analysis of randomized controlled trials. BMC Med 2014, 12:60.

6. Lin JS, O'Connor E, Whitlock EP, Beil TL: Behavioral counseling to promote physical activity and a healthful diet to prevent cardiovascular disease in adults: a systematic review for the U.S. preventive services task force. Ann Intern Med 2010, 153:736-750.

7. Moyer VA: Behavioral counseling interventions to promote a healthful diet and physical activity for cardiovascular disease prevention in adults: U.S. preventive services task force recommendation statement. Ann Intern Med 2012, 157:367-372. 
8. Davidson K, Goldstein M, Kaplan R, Kaufmann P, Knatterud G, Orleans CT, Spring B, Trudeau K, Whitlock E: Evidence-based behavioral medicine: what is it and how do we achieve it? Ann Behav Med 2003, 26:161-171.

9. Michie S, Abraham C, Whittington C, McAteer J, Gupta S: Effective techniques in healthy eating and physical activity interventions: a meta-regression. Health Psychol 2009, 28:690-701.

10. Michie S, Ashford S, Sniehotta FF, Dombrowski SU, Bishop A, French DP: A refined taxonomy of behaviour change techniques to help people change their physical activity and healthy eating behaviours: the CALO-RE taxonomy. Psychol Health 2011, 26:1479-1498.

11. Olander $E$, Fletcher $H$, Williams S, Atkinson L, Turner A, French D: What are the most effective techniques in changing obese individuals' physical activity self-efficacy and behaviour: a systematic review and meta-analysis. Int J Behav Nutr Phys Act 2013, 10:29.

12. French D, Olander E, Chisholm A, Mc Sharry J: Which behaviour change techniques are most effective at increasing older adults' self-efficacy and physical activity behaviour? A systematic review. Ann Behav Med 2014, 48:1-10.

13. Gardner B, Wardle J, Poston L, Croker H: Changing diet and physical activity to reduce gestational weight gain: a meta-analysis. Obes Rev 2011, 12:e602-e620.

14. Hill B, Skouteris H, Fuller-Tyszkiewicz M: Interventions designed to limit gestational weight gain: a systematic review of theory and meta-analysis of intervention components. Obes Rev 2013, 14:435-450.

15. Hartmann-Boyce J, Johns DJ, Jebb SA, Aveyard P: Effect of behavioural techniques and delivery mode on effectiveness of weight management: systematic review, meta-analysis and meta-regression. Obes Rev 2014, 15:598-609.

16. Martin J, Chater A, Lorencatto F: Effective behaviour change techniques in the prevention and management of childhood obesity. Int J Obes (Lond) 2013, 37:1287-1294.

17. Moher D, Liberati A, Tetzlaff J, Altman DG: Preferred reporting items for systematic reviews and meta-analyses: the PRISMA statement. BMJ 2009, 339:b2535.

18. Tilley BC, Glanz K, Kristal AR, Hirst K, Li S, Vernon SW, Myers R: Nutrition intervention for high-risk auto workers: results of the Next Step Trial. Prev Med 1999, 28:284-292.

19. Bemelmans WJ, Broer J, de Vries JH, Hulshof KF, May JF, Meyboom-De Jong B: Impact of Mediterranean diet education versus posted leaflet on dietary habits and serum cholesterol in a high risk population for cardiovascular disease. Public Health Nutr 2000, 3:273-283.

20. Werkman A, Hulshof PJ, Stafleu A, Kremers SP, Kok FJ, Schouten EG, Schuit AJ: Effect of an individually tailored one-year energy balance programme on body weight, body composition and lifestyle in recent retirees: a cluster randomised controlled trial. BMC Public Health 2010, 10:110.

21. Wright J, Sherriff J, Dhaliwal S, Mamo J: Tailored, iterative, printed dietary feedback is as effective as group education in improving dietary behaviours: results from a randomised control trial in middle-aged adults with cardiovascular risk factors. Int J Behav Nutr Phys Act 2011, 8:43.

22. Kanaya AM, Santoyo-Olsson J, Gregorich S, Grossman M, Moore T, Stewart AL: The live well, be well study: a community-based, translational lifestyle program to lower diabetes risk factors in ethnic minority and lowersocioeconomic status adults. Am J Public Health 2012, 102:1551-1558.

23. Little P, Kelly J, Barnett J, Dorward M, Margetts B, Warm D: Randomised controlled factorial trial of dietary advice for patients with a single high blood pressure reading in primary care. BMJ 2004, 328:1054.

24. Marcus AC, Heimendinger J, Wolfe P, Fairclough D, Rimer BK, Morra M, Warnecke R, Himes JH, Darrow SL, Davis SW, Julesberg K, Slevin-Perocchia R, Steelman $\mathrm{M}$, Wooldridge J: A randomized trial of a brief intervention to increase fruit and vegetable intake: a replication study among callers to the CIS. Prev Med 2001, 33:204-216.

25. Takahashi Y, Sasaki S, Okubo S, Hayashi M, Tsugane S: Blood pressure change in a free-living population-based dietary modification study in Japan. J Hypertens 2006, 24:451-458.

26. Estruch R, Ros E, Salas-Salvado J, Covas MI, Corella D, Aros F, Gomez-Gracia E, Ruiz-Gutierrez V, Fiol M, Lapetra J, Lamuela-Raventos RM, Serra-Majem L, Pintó X, Basora J, Muñoz MA, Sorlí JV, Martínez JA, Martínez-González MA, PREDIMED Study Investigators: Primary prevention of cardiovascular disease with a Mediterranean diet. N Engl J Med 2013, 368:1279-1290.

27. Campbell MK, Demark-Wahnefried W, Symons M, Kalsbeek WD, Dodds J, Cowan A, Jackson B, Motsinger B, Hoben K, Lashley J, Demissie S, McClelland
JW: Fruit and vegetable consumption and prevention of cancer: the Black Churches United for Better Health project. Am J Public Health 1999, 89:1390-1396

28. Stevens VJ, Glasgow RE, Toobert DJ, Karanja N, Smith KS: One-year results from a brief, computer-assisted intervention to decrease consumption of fat and increase consumption of fruits and vegetables. Prev Med 2003, 36:594-600.

29. Howard BV, Curb JD, Eaton CB, Kooperberg C, Ockene J, Kostis JB, Pettinger M, Rajkovic A, Robinson JG, Rossouw J, Sarto G, Shikany JM, Van Horn L: Low-fat dietary pattern and lipoprotein risk factors: the Women's Health Initiative Dietary Modification Trial. Am J Clin Nutr 2010, 91:860-874.

30. Wolf RL, Lepore SJ, Vandergrift JL, Basch CE, Yaroch AL: Tailored telephone education to promote awareness and adoption of fruit and vegetable recommendations among urban and mostly immigrant black men: a randomized controlled trial. Prev Med 2009, 48:32-38.

31. Walker SN, Pullen CH, Boeckner L, Hageman PA, Hertzog M, Oberdorfer MK, Rutledge MJ: Clinical trial of tailored activity and eating newsletters with older rural women. Nurs Res 2009, 58:74-85.

32. Merrill RM, Aldana SG: Consequences of a plant-based diet with low dairy consumption on intake of bone-relevant nutrients. J Womens Health (Larchmt) 2009, 18:691-698.

33. Lapointe A, Weisnagel SJ, Provencher V, Begin C, Dufour-Bouchard AA, Trudeau C, Lemieux S: Using restrictive messages to limit high-fat foods or nonrestrictive messages to increase fruit and vegetable intake: what works better for postmenopausal women? Eur J Clin Nutr 2010, 64:194-202.

34. Lanza E, Schatzkin A, Daston C, Corle D, Freedman L, Ballard-Barbash R, Caan B, Lance P, Marshall J, Iber F, Shike M, Weissfeld J, Slattery M, Paskett E, Mateski D, Albert P, PPT Study Group: Implementation of a 4-y, high-fiber, high-fruit-and-vegetable, low-fat dietary intervention: results of dietary changes in the Polyp Prevention Trial. Am J Clin Nutr 2001, 74:387-401.

35. Iso H, Imano H, Nakagawa Y, Kiyama M, Kitamura A, Sato S, Naito Y, Shimamoto T, lida M: One-year community-based education program for hypercholesterolemia in middle-aged Japanese: a long-term outcome at 8-year follow-up. Atherosclerosis 2002, 164:195-202.

36. van Keulen $\mathrm{H}$, Mesters I, Ausems M, Breukelen G, Campbell M, Resnicow K, Brug J, Vries H: Tailored print communication and telephone motivational interviewing are equally successful in improving multiple lifestyle behaviors in a randomized controlled trial. Ann Behav Med 2011, 41:104-118.

37. Bowen DJ, Beresford SA, Christensen CL, Kuniyuki AA, McLerran D, Feng Z, Hart A Jr, Tinker L, Campbell M, Satia J: Effects of a multilevel dietary intervention in religious organizations. Am J Health Promot 2009, 24:15-22.

38. Panunzio MF, Caporizzi R, Antoniciello A, Cela EP, Ferguson LR, D'Ambrosio P: Randomized, controlled nutrition education trial promotes a Mediterranean diet and improves anthropometric, dietary, and metabolic parameters in adults. Ann Ig 2011, 23:13-25.

39. Coates RJ, Bowen DJ, Kristal AR, Feng Z, Oberman A, Hall WD, George V, Lewis CE, Kestin M, Davis M, Evans M, Grizzle JE, Clifford CK: The women's health trial feasibility study in minority populations: changes in dietary intakes. Am J Epidemiol 1999, 149:1104-1112.

40. Higgins JP, Green S: Cochrane Collaboration: Cochrane Handbook for Systematic Reviews of Interventions. Chichester, West Sussex; Hoboken NJ: Wiley-Blackwell; 2008.

41. University of York. NHS Centre for Reviews \& Dissemination: Systematic Reviews: CRD's Guidance for Undertaking Reviews in Health Care. York: Centre for Reviews and Dissemination, University of York; 2009.

42. Ioannidis JP, Patsopoulos NA, Evangelou E: Uncertainty in heterogeneity estimates in meta-analyses. BMJ 2007, 335:914-916.

43. Higgins JP, Thompson SG: Quantifying heterogeneity in a meta-analysis. Stat Med 2002, 21:1539-1558.

44. Egger M, Davey Smith G, Schneider M, Minder C: Bias in meta-analysis detected by a simple, graphical test. BMJ 1997, 315:629-634.

45. Bandura A: Social cognitive theory: an agentic perspective. Annu Rev Psychol 2001, 52:1-26.

46. Skinner BF: Science and Human Behavior. New York: Macmillan; 1953.

47. Prestwich A, Sniehotta FF, Whittington C, Dombrowski SU, Rogers L, Michie S: Does theory influence the effectiveness of health behavior interventions? Meta-analysis. Health Psychol 2014, 33:465-474.

48. Vaupel JW: Biodemography of human ageing. Nature 2010, 464:536-542.

49. Nooyens AC, Visscher TL, Schuit AJ, van Rossum CT, Verschuren WM, van Mechelen W, Seidell JC: Effects of retirement on lifestyle in relation to changes in weight and waist circumference in Dutch men: a prospective study. Public Health Nutr 2005, 8:1266-1274. 
50. Wilson DM, Palha P: A systematic review of published research articles on health promotion at retirement. J Nurs Scholarsh 2007, 39:330-337.

51. Mills A, Patel S: Food Portion Sizes. 2nd edition. London: HMSO; 1993.

52. World Health Organization: Diet, nutrition and the prevention of chronic diseases. Report of a Joint WHO/FAO Expert Consultation (WHO Technical Report Series 916). Geneva: WHO; 2003.

53. Dauchet L, Amouyel P, Dallongeville J: Fruit and vegetable consumption and risk of stroke: a meta-analysis of cohort studies. Neurology 2005, 65:1193-1197.

54. He FJ, Nowson CA, MacGregor GA: Fruit and vegetable consumption and stroke: meta-analysis of cohort studies. Lancet 2006, 367:320-326.

55. Dauchet L, Amouyel P, Hercberg S, Dallongeville J: Fruit and vegetable consumption and risk of coronary heart disease: a meta-analysis of cohort studies. J Nutr 2006, 136:2588-2593.

56. Carter P, Gray L, Troughton J, Khunti K, Davies MJ: Fruit and vegetable intake and incidence of type 2 diabetes mellitus: systematic review and meta-analysis. BMJ 2010, 341:C4229.

57. Cooper AJ, Forouhi NG, Ye Z, Buijsse B, Arriola L, Balkau B, Barricarte A, Beulens JWJ, Boeing H, Buchner FL, Dahm CC, de Lauzon-Guillain B, Fagherazzi G, Franks PW, Gonzalez C, Grioni S, Kaaks R, Key TJ, Masala G, Navarro C, Nilsson P, Overvad K, Panico S, Ramón Quirós J, Rolandsson O, Roswall N, Sacerdote C, Sánchez MJ, Slimani N, Sluijs I, et al: Fruit and vegetable intake and type 2 diabetes: EPIC-InterAct prospective study and meta-analysis. Eur J Clin Nutr 2012, 66:1082-1092.

doi:10.1186/s12916-014-0177-3

Cite this article as: Lara et al:: Association of behaviour change techniques with effectiveness of dietary interventions among adults of retirement age: a systematic review and meta-analysis of randomised controlled trials. BMC Medicine 2014 12:177.

\section{Submit your next manuscript to BioMed Central and take full advantage of:}

- Convenient online submission

- Thorough peer review

- No space constraints or color figure charges

- Immediate publication on acceptance

- Inclusion in PubMed, CAS, Scopus and Google Scholar

- Research which is freely available for redistribution 